\title{
Prediction of stability limit for multi-regenerative chatter in high performance milling
}

\author{
Qiang Guo · Yuwen Sun · Yan Jiang · Dongming Guo
}

Received: 16 August 2013 / Revised: 24 December 2013 / Accepted: 26 December 2013 / Published online: 18 January 2014

(C) Springer-Verlag Berlin Heidelberg 2014

\begin{abstract}
Chatter is one of the most important factors that inhibit the improvement of productivity and deteriorate the machined surface quality in milling process. In order to obtain good surface quality, classical machining process usually has to take conservative milling parameters. Based on the authors' previous work, this paper presented a new thirdorder discretization method to compute the stability lobes considering multi-regenerative chatter effect. A mathematical model, which is suitable for the dynamic system with non-uniform pitch cutter or cutter run-out, is first established for multi-regenerative chatter. Then, three examples are performed to test the validity of the proposed method. The first example is for the case that the system takes a non-uniform pitch cutter. In the second example, after the modal parameters, run-out parameters and cutting force parameters are gained from experiments, the stability lobes are predicted using the proposed method and subsequently testified by a series of experiments. The third example is for the case of existing cutter run-out. The final computation and experiment results indicate the effectiveness and validity of the proposed method. It is applicable in high performance machining for achieving a good parameter combination.
\end{abstract}

Q. Guo · Y. Sun $(\bowtie) \cdot$ D. Guo

Key Laboratory for Precision and Non-Traditional Machining

Technology of the Ministry of Education, Dalian University

of Technology, Dalian 116024, China

e-mail: xiands@dlut.edu.cn

Q. Guo

School of Mechanical and Power Engineering, Henan Polytechnic

University, Jiaozuo 454150, China

Y. Jiang

School of Survey and Land Information Engineering, Henan

Polytechnic University, Jiaozuo 454150, China
Keywords Multi-regenerative - Stability lobes $\cdot$ Run-out · Non-uniform pitch angle $\cdot$ Milling process

\section{Introduction}

In milling process, machining chatter often leads to several negative effects such as poor surface quality, unacceptable inaccuracy and reduced material removal rate [1]. For these reasons, stability limit prediction and chatter avoidance have become the key issues in high performance milling $[2,3]$ so as to acquire maximum chatter-free matter removal rate. The stability lobe diagram, which is helpful for selecting stable and reliable cutting parameter combinations, is usually derived based on the delay-differential equations (DDEs) $[4,5]$ embracing the regeneration of instantaneous uncut chip thickness. For a specific process system, once the location of stability limit of the milling process is given, one can determine suitable axial depth of cut and spindle speed rapidly and effectively.

During milling process, chatter vibration is possibly excited by the dynamic interactions between the cutting tool and workpiece [6-9]. If the current cutting edge removes the material left by the first previous cutting edge, the single regenerative effect of chatter vibration occurs. Otherwise, the multiple regenerative effect of chatter vibration occurs. When the cutter run-out exists or the pitch angle of the cutter is non-uniform, the chatter vibration is induced by multiple, not single, regenerative effect. The first accurate model of self-excited chatter vibrations was presented by Tlusty and Polacek [10] and Tobias [11]. They found that the main source of chatter vibration is self-excited or regenerative effect. For the model of the chatter vibration is DDE, there has been no analytical solution. So the calculation method of this equation usually uses numerical method, experimental method [12] or experimental-analytical method [13]. 
Currently, some numerical methods have been developed. One way of the numerical methods computes the DDEs in frequency domain, Minis and Yanushevsky [14] used Floquet's theory and the Fourier series to calculate the milling stability of dynamic system. Altintas and Budak [12,15-18] have made great efforts on computing the stability lobes in the frequency domain. The basic idea of their methods to predict stability limit is translating DDEs from time domain to frequency domain using Fourier Transform. And then, by means of Fourier transform the stability lobes are calculated using the real and image part of the characteristic equation of the dynamic system. The method has been widely verified [12,18,19], and also is applied to ball-end milling [20], predicting the stability lobes of the dynamic system with non-uniform pitch angle cutter $[13,16]$ as well as with cutter considering helix angle [21-23]. In addition, utilizing the method, Kivanc and Budak $[24,25]$ took finite element analysis (FEA) as a tool to obtain modal parameters of the dynamic system and then predicted stability lobes based on these parameters. Ozlu and Budak [26,27] also took this theory as a foundation to propose a method for predicting stability limits in turning and boring operations.

Another numerical way to predict stability lobes of the dynamic system is in time domain, the main advantage of this way is that it can prevent the transformation error induced by Fourier Transform. The basic theory of this method is introducing finite element ideology into the time domain. In this respect, Insperger et al. [28-31] proposed an extremely significant semi-discretization method (SDM) to predict the stability lobes and analyze the influence of cutter runout on the chatter frenquences. The method has been proved by Catania and Mancinelli [32] and has already aroused more and more attention. In addition, literatures [33,34] also developed numerical methods to predict the stability lobes. Recently, Ding et.al [35] introduced a numerical integration scheme to obtain the stablity lobes, and then they $[36,37]$ developed first-order and second-order full-discretization methods (FDM). Subsequently, Zhang et al. [38] presented a variablestep integration FDM method for milling chatter stability prediction with multiple delays. Between the SDM and FDM, some comparations have been made to show their own advantages [39].

In our previous works [40], an accurate calculation method of milling stability limits have been proposed. In the present work, the basic principle of the milling stability prediction method has been further extended from single to multiple regenerative chatter to predict stability lobes of the dynamic system with nonuniform pitch cutter or cutter runout. Then three examples are conducted to verify the accuracy and validity of the proposed method. The dynamic system with variable pitch cutter is given in the first example and the results are also compared with the methods in existing literatures. The second example conducts a series of experiments

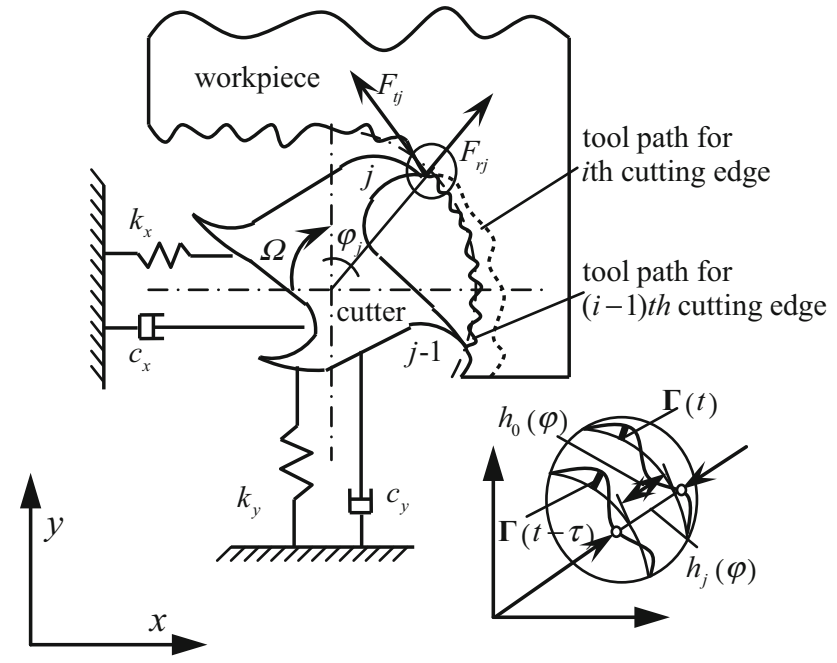

Fig. 1 The schematic diagram of dynamic milling system

to verify the validity of the proposed method. And the third example analyzes the influence of cutter runout parameters on the stability lobes.

\section{Mechanical model}

Figure 1 shows the schematic diagram of a dynamic machining system. In this figure, cutter edges' radius as well as pitch angles are different from each other. This can result in that the cutting edge removes the material lefted by $j$ th cutter edge, where $j=(1,2,3, \ldots, N)$. And cutting edges' passing periods may not be equal to the ideal value. In this case, multi-regenerative chatter occurs. The mathematical model of this dynamic system can be expressed using the following equation

$$
\begin{aligned}
& \mathbf{M} \frac{d^{2} \mathbf{q}(t)}{d t^{2}}+\mathbf{C} \frac{d \mathbf{q}(t)}{d t}+\mathbf{K q}(t) \\
& \quad=a \sum_{j=1}^{N}\left(\mathbf{K}_{c j}(t)\left[\mathbf{q}\left(t-\tau_{j}\right)-\mathbf{q}(t)\right]\right)
\end{aligned}
$$

where

$\left\{\begin{array}{l}\mathbf{M}=\left[\begin{array}{cc}m_{x} & 0 \\ 0 & m_{y}\end{array}\right], \mathbf{C}=\left[\begin{array}{cc}c_{x} & 0 \\ 0 & c_{y}\end{array}\right], \mathbf{K}=\left[\begin{array}{cc}k_{x} & 0 \\ 0 & k_{y}\end{array}\right] \\ \mathbf{q}=\left[\begin{array}{ll}x(t) & y(t)\end{array}\right]^{T}, K_{c j}(t)=\frac{1}{2}\left[\begin{array}{ll}a_{j, x x} & a_{j, x y} \\ a_{j, y x} & a_{j, y y}\end{array}\right]\end{array}\right.$

and

$\left\{\begin{array}{l}a_{j, x x}=g\left(\varphi_{j}\right)\left[K_{r} \sin \left(2 \varphi_{j}\right)-K_{t}\left(\cos \left(2 \varphi_{j}\right)-1\right)\right] \\ a_{j, x y}=g\left(\varphi_{j}\right)\left[K_{t} \sin \left(2 \varphi_{j}\right)+K_{r}\left(\cos \left(2 \varphi_{j}\right)+1\right)\right] \\ a_{j, y x}=g\left(\varphi_{j}\right)\left[K_{t} \sin \left(2 \varphi_{j}\right)-K_{r}\left(\cos \left(2 \varphi_{j}\right)-1\right)\right] \\ a_{j, y y}=g\left(\varphi_{j}\right)\left[K_{r} \sin \left(2 \varphi_{j}\right)+\left(\cos \left(2 \varphi_{j}\right)-1\right) K_{t}\right]\end{array}\right.$ 
In the above formula, $g\left(\varphi_{j}\right)$ is $0-1$ function which determines whether the cutter edge is removing material or not. And this function can be expressed as

$$
\left\{\begin{array}{l}
g\left(\varphi_{j}\right)=1 \quad \text { when } \varphi_{s t} \leq \varphi_{j} \leq \varphi_{e x} \\
g\left(\varphi_{j}\right)=0 \quad \text { when } \varphi_{s t}>\varphi_{j} \text { or } \varphi_{j}>\varphi_{e x}
\end{array}\right.
$$

where $\varphi_{s t}$ and $\varphi_{e x}$ stand for the entering and exiting cutting angle, respectively, $\varphi_{j}$ is the rotation angle for $j$ th cutter edge and it should transform into $[0,2 \pi]$ using: while $\varphi_{j}>$ $2 \pi, \varphi_{j}=\varphi_{j}-2 \pi$ and while $\varphi_{j}<0, \varphi_{j}=\varphi_{j}+2 \pi$.

For variable pitch angle cutter and constant pitch angle with cutter run-out, there are some differences in the parameters of milling process such as entering and exiting angle in Eq. 2 and the cutting radius of the cutter edge between them. Therefore, it is necessary to describe these factors firstly.

\subsection{Milling process with non-uniform pitch angles}

When the cutter with non-uniform pitch angles is used in milling process, $\tau_{j}$ in Eq. 1 is not spindle rotational period but tooth pass period. And $\tau_{j}$ can be expressed using the following equation

$\tau_{j}=\frac{60 \phi_{j, j-1}}{2 \pi n}$

where $\phi_{j, j-1}$ is the pitch angle between $j$ th and $(j-1)$ th cutter edge, and when $j=1$ it is the pitch angle between first cutter edge and $N$ th cutter edge. $n$ is the spindle speed in revolution per minute. It can be seen that the sum of all teeth's periods of the cutter is equal to the spindle period.

$\sum_{j=1}^{N} \tau_{j}=\sum_{j=1}^{N}\left(\frac{60 \phi_{j, j-1}}{2 \pi n}\right)=T=\frac{60}{n}$

And the entering angle and exiting angle of the cutter with non-uniform pitch angles can be computed using the following equation

$$
\left\{\begin{array}{l}
\varphi_{s t}=\pi / 2+\arcsin \left[\left(R-a_{p}\right) / R\right] \\
\varphi_{e x}=\pi
\end{array}\right.
$$

This equation is used under the situation that the machining process is down milling. For the up milling process, entering angle becomes exiting angle and exiting angle becomes entering angle in Eq. 5. That is

$$
\left\{\begin{array}{l}
\varphi_{s t}=\pi \\
\varphi_{e x}=\pi / 2+\arcsin \left[\left(R-a_{p}\right) / R\right]
\end{array}\right.
$$

It is worth nothing that the rotation angle of $j$ th cutter edge of the non-uniform cutter is different from the value of the cutter with uniform pitch angle. It can be calculated utilizing the following equation

$\varphi_{j}(t)=\alpha+2 \pi n t+\sum_{i=1}^{j} \phi_{i, i-1}$ where $\alpha$ is the initial angle between the first cutter edge and the positive $y$-axis at time $t=0$.

\subsection{Milling process with run-out}

More or less, the cutter run-out exists in machining process. When considering the cutter run-out effect, the real cutting radius of the cutter edge and pitch angle will deviate from their ideal values. Therefore, it is necessary to compute these real values of the cutting radius and pitch angle and so on.

The cutting radius of the cutter edge can be expressed using the following equation

if $\pi-\lambda-2(i-1) \pi / N>0$

$$
R_{i}=\sqrt{\rho^{2}+R^{2}-2 \rho R \cos (\pi-\lambda-2(i-1) \pi / N)}
$$

else

$$
R_{i}=\sqrt{\rho^{2}+R^{2}-2 \rho R \cos (\lambda+2(i-1) \pi / N-\pi)}
$$

where $R$ is the nominal cutting radius of the cutter edge, and $R_{i}$ is the actual cutting radius of $i$ th cutter edge when existing cutter run-out. $\rho$ is the offset parameter and $\lambda$ is the location angle of the cutter run-out.

Owing to the change of the cutting radius in milling with cutter run-out effect, the pitch angle is also different from its nominal value, and it can be calculated as

if $i==1$

$$
\phi_{N 1}=a \cos \left(\left(R_{N}^{2}+R_{1}^{2}-R_{c}^{2}\right) / 2 R_{N} R_{1}\right)
$$

else

$$
\phi_{(i-1) i}=a \cos \left(\left(R_{i-1}^{2}+R_{i}^{2}-R_{c}^{2}\right) / 2 R_{i-1} R_{i}\right)
$$

where $\phi_{N, 1}$ is the pitch angle between the $N$ th and 1 th cutter edge, and $R_{c}^{2}=2 R^{2}(1-\cos (2 \pi / N))$.

Then, taking down milling as an example, the entry and exit angles can be obtainedutilizing the following formula

$$
\begin{aligned}
& \phi_{i, s t}=\pi / 2+a \sin \left(\left(R_{i}-a_{r}\right) / R_{i}\right) \\
& \text { if } i==1 \\
& \qquad \phi_{1, \mathrm{e} x}=\pi / 2+a \cos \left(\left(\left(f_{t, 1}\right)^{2}+R_{1}^{2}-R_{N}^{2}\right) / 2 f_{t, 1} R_{1}\right)
\end{aligned}
$$

else

$$
\phi_{i, e x}=\pi / 2+a \cos \left(\left(\left(f_{t, i}\right)^{2}+R_{i}^{2}-R_{i-1}^{2}\right) / 2 f_{t, i} R_{i}\right)
$$

where $\phi_{i, s t}$ and $\phi_{i, e x}$ are the entry and exit angle correspondingly. $f_{t, i}$ and $f_{t, 1}$ are the real feedrate per tooth for the $i$ th and $l$ th cutter edge

$$
\text { if } \begin{aligned}
i= & =1 \\
f_{t, 1} & =f_{t} \phi_{N 1} / 2 \pi
\end{aligned}
$$

else

$$
f_{t, i}=f_{t} \phi_{(i-1) i} / 2 \pi
$$

where $f$ stands for the nominal feedrate per tooth. 
Thus, the stability lobes of milling process with nonuniform pitch angle and cutter run-out can be calculated. The next section will introduce the method of predicting the stability limits for multiple delays described by Eq. 1.

\section{Stability prediction for multiple delays}

In order to predict the stability lobes for multiple delays, a third-order full discretization method is proposed in this paper.

\subsection{Third-order discretization}

The formula of Eq. 1 is simplified utilizing the following method to obtain first order differential equations

$$
\frac{d \mathbf{x}(t)}{d t}=\mathbf{A}_{0} \mathbf{x}(t)+\sum_{j=1}^{N}\left[\mathbf{A}_{j}(t) \mathbf{x}(t)+\mathbf{B}_{j}(t) \mathbf{x}\left(t-\tau_{j}\right)\right]
$$

where $\mathbf{A}_{0}$ is the constant matrix standing for the time invariants of the dynamic system. $\mathbf{A}_{j}(t)$ and $\mathbf{B}_{j}(t)$ are two periodic functions with the period $\tau_{j}$ for $j$ th cutter axis. $\mathbf{x}(t)$ is the state variable of the system. $\mathbf{A}_{0}, \mathbf{x}(t), \mathbf{A}_{j}(t)$ and $\mathbf{B}_{j}(t)$ can be expressed by the following equations

$$
\begin{aligned}
& \mathbf{A}_{0}=\left[\begin{array}{cc}
-\frac{\mathbf{M}^{-1} \mathbf{C}}{2} & \mathbf{M}^{-1} \\
\frac{\mathbf{C M}^{-1} \mathbf{C}^{2}}{4}-\mathbf{K} & -\frac{\mathbf{M}^{-1} \mathbf{C}}{2}
\end{array}\right] \\
& \mathbf{x}(t)=\left[\begin{array}{lll}
\mathbf{q}(t) & \mathbf{M} \frac{d \mathbf{q}(t)}{d t}+\frac{\mathbf{C q}(t)}{2}
\end{array}\right]^{T} \\
& \mathbf{B}_{j}(t)=-\mathbf{A}_{j}(t)=\frac{a}{2}\left[\begin{array}{cc}
\mathbf{0} & \mathbf{0} \\
\mathbf{K}_{c j}(t) & \mathbf{0}
\end{array}\right]
\end{aligned}
$$

In order to obtain the stability lobes of the dynamic system, the first step is to divide the $j$ th cutter rotational period $\tau_{j}$ into $m_{j}$ time-intervals, and $m_{j}$ can be calculated by

$$
\left\{\begin{array}{l}
m_{j}=\text { round }\left(\tau_{j} / h\right) \\
h=T / m \\
m=\sum_{j=1}^{N} m_{j}
\end{array}\right.
$$

where round() stands for the rounding operation, such as round(3.2) $=3$ and round $(3.6)=4$. For the $k$ th time-interval of the $j$ th cutter rotational period, the solution of this time delay differential equation with multi-regenerative effect can be calculated by

$$
\left\{\begin{array}{l}
\mathbf{x}_{m(j, k+1)}=e^{\mathbf{A}_{0} h} \mathbf{x}_{m(j, k)} \\
+\sum_{j=1}^{N}\left(\int_{0}^{h} e^{\mathbf{A}_{0}(h-\varepsilon)}\left[\begin{array}{l}
\mathbf{A}(\varepsilon) \mathbf{x}(\varepsilon) \\
+\mathbf{B}(\varepsilon) \mathbf{x}\left(\varepsilon-\tau_{j}\right)
\end{array}\right] d \varepsilon\right) \\
m(j, k+1)=\sum_{l=1}^{j-1} m_{l}+k+1
\end{array}\right.
$$

with $h=T / m$ and $m=\operatorname{sum}\left(m_{1}, \ldots, m_{N}\right), \varepsilon \in[0, \mathrm{~h}]$.
The next step is to solve Eq. (17) using one and third-order interpolation theory. For the $k$ th time interval, $\mathbf{A}(\varepsilon), \mathbf{B}(\varepsilon)$ and $\mathbf{x}\left(\varepsilon-\tau_{j}\right)$ are correspondingly interpolated by two boundaries

$$
\begin{aligned}
& {\left[\begin{array}{ll}
\mathbf{A}_{m(j, k)} & \mathbf{A}_{m(j, k+1)}
\end{array}\right],\left[\begin{array}{ll}
\mathbf{B}_{m(j, k)} & \mathbf{B}_{m(j, k+1)}
\end{array}\right]} \\
& \quad \text { and }\left[\begin{array}{ll}
\mathbf{x}_{m(j, k-m)} & \mathbf{x}_{m(j, k-m+1)}
\end{array}\right]
\end{aligned}
$$

with

$\mathbf{A}(\varepsilon) \approx \frac{\varepsilon}{h} \mathbf{A}_{m(j, k+1)}+\frac{h-\varepsilon}{h} \mathbf{A}_{m(j, k)}$

$\mathbf{B}(\varepsilon) \approx \frac{\varepsilon}{h} \mathbf{B}_{m(j, k+1)}+\frac{h-\varepsilon}{h} \mathbf{B}_{m(j, k+1)}$

$\mathbf{x}\left(\varepsilon-\tau_{j}\right) \approx \frac{\varepsilon}{h} \mathbf{x}_{m(j, k-m+1)}+\frac{h-\varepsilon}{h} \mathbf{x}_{m(j, k-m)}$

where $\mathbf{x}(\varepsilon)$ can be approximated by third-order Newton's interpolation equation using $\mathbf{x}_{m(j, k+1)}, \mathbf{x}_{m(j, k)}, \mathbf{x}_{m(j, k-1)}$ and $\mathbf{x}_{m(j, k-1)}$ with following expression

$$
\begin{aligned}
& \mathbf{x}_{m(j, k+1)}=\left(\mathbf{I}-\mathbf{F}_{1}\right)^{-1} \\
& \times\left[\begin{array}{l}
\left(\mathbf{F}_{0}+\mathbf{F}_{2}\right) \mathbf{x}_{m(j, k)}+\mathbf{F}_{3} \mathbf{x}_{m(j, k-1)} \\
+\mathbf{F}_{4} \mathbf{x}_{m(j, k-2)}+\sum_{j=1}^{N}\left(\mathbf{F}_{j, m-1} \mathbf{x}_{m\left(j, k-m_{j}\right)}\right) \\
+\sum_{j=1}^{N}\left(\mathbf{F}_{j, m} \mathbf{x}_{m\left(j, k-m_{j}+1\right)}\right)
\end{array}\right]
\end{aligned}
$$

with

$$
\begin{aligned}
\mathbf{F}_{1}= & \frac{\mathbf{f}_{0}\left(\mathbf{f}_{5}+3 h \mathbf{f}_{4}+h^{2} \mathbf{f}_{3}\right)}{6 h^{4}} \sum_{j=1}^{N} \mathbf{A}_{m(j, k+1)} \\
& +\frac{\mathbf{f}_{0}\left(2 h^{3} \mathbf{f}_{2}+h^{2} \mathbf{f}_{3}-2 h \mathbf{f}_{4}-\mathbf{f}_{5}\right)}{6 h^{4}} \sum_{j=1}^{N} \mathbf{A}_{m(j, k)}
\end{aligned}
$$

$$
\begin{aligned}
\mathbf{F}_{2}= & \frac{\mathbf{f}_{0}\left(\mathbf{f}_{4}+3 h \mathbf{f}_{3}+2 h^{2} \mathbf{f}_{2}\right)}{2 h^{3}} \sum_{j=1}^{N} \mathbf{A}_{m(j, k+1)} \\
& +\frac{\mathbf{f}_{0}\left(6 h^{3} \mathbf{f}_{1}+3 h^{2} \mathbf{f}_{2}-6 h \mathbf{f}_{3}-\mathbf{f}_{4}\right)}{6 h^{3}} \sum_{j=1}^{N} \mathbf{A}_{m(j, k)}-3 \mathbf{F}_{1}
\end{aligned}
$$

$$
\begin{aligned}
\mathbf{F}_{3}= & \frac{\mathbf{f}_{0}\left(\mathbf{f}_{3}+2 h \mathbf{f}_{2}\right)}{h^{2}} \sum_{j=1}^{N} \mathbf{A}_{m(j, k+1)} \\
& +\frac{\mathbf{f}_{0}\left(2 h^{2} \mathbf{f}_{1}-h \mathbf{f}_{2}-\mathbf{f}_{3}\right)}{h^{2}} \sum_{j=1}^{N} \mathbf{A}_{m(j, k)}-2 \mathbf{F}_{2}-3 \mathbf{F}_{1}
\end{aligned}
$$

$$
\begin{aligned}
\mathbf{F}_{4}= & \mathbf{f}_{0} \frac{\mathbf{f}_{2}}{h} \sum_{j=1}^{N} \mathbf{A}_{m(j, k+1)} \\
& +\mathbf{f}_{0}\left(\mathbf{f}_{1}-\frac{\mathbf{f}_{2}}{h}\right) \sum_{j=1}^{N}\left(\mathbf{A}_{m(j, k)}\right)-\mathbf{F}_{2}-\mathbf{F}_{1}-\mathbf{F}_{3}
\end{aligned}
$$




$$
\begin{aligned}
& \mathbf{F}_{j, m-1}=\left(\mathbf{f}_{0} \mathbf{f}_{3} / h^{2}\right) \mathbf{B}_{m(j, k+1)}+\left(\mathbf{f}_{0}\left(h \mathbf{f}_{2}-\mathbf{f}_{3}\right) / h^{2}\right) \mathbf{B}_{m(j, k)} \quad \mathbf{f}_{1}=\mathbf{A}_{0}^{-1}\left(\mathbf{I}-\mathbf{f}_{0}^{-1}\right) \\
& \mathbf{F}_{j, m}=\left(\mathbf{f}_{0}\left(h \mathbf{f}_{2}-\mathbf{f}_{3}\right) / h^{2}\right) \mathbf{B}_{m(j, k+1)} \\
& +\left(\mathbf{f}_{0}\left(h^{2} \mathbf{f}_{1}-2 h \mathbf{f}_{2}+\mathbf{f}_{3}\right) / h^{2}\right) \mathbf{B}_{m(j, k)}
\end{aligned}
$$

$$
\begin{aligned}
& \mathbf{F}_{0}=\mathbf{f}_{0}=e^{\mathbf{A}_{0} h} \\
& \mathbf{f}_{1}=\int_{0}^{h} e^{-\mathbf{A}_{0} \varepsilon} d \varepsilon \\
& \mathbf{f}_{2}=\int_{0}^{h} e^{-\mathbf{A}_{0} \varepsilon} \varepsilon d \varepsilon \\
& \mathbf{f}_{3}=\int_{0}^{h} e^{-\mathbf{A}_{0} \varepsilon} \varepsilon^{2} d \varepsilon \\
& \mathbf{f}_{4}=\int_{0}^{h} e^{-\mathbf{A}_{0} \varepsilon} \varepsilon^{3} d \varepsilon \\
& \mathbf{f}_{5}=\int_{0}^{h} e^{-\mathbf{A}_{0} \varepsilon} \varepsilon^{4} d \varepsilon
\end{aligned}
$$

Further, $\mathbf{f}_{1}, \mathbf{f}_{2}, \mathbf{f}_{3}, \mathbf{f}_{4}$ and $\mathbf{f}_{5}$ in Eqs. (16)-(20) can be expressed using the following forms.

Then, Eq. (21) named as iterated function can be expressed in another form, e.g. in matrix form

$\mathbf{Y}_{m(j, k+1)}=\mathbf{D}_{m(j, k)} \mathbf{Y}_{m(j, k)}$

In this equation, the column vector $\mathbf{Y}_{m(j, k+1)}$ can be expressed by the following equation

$$
\begin{aligned}
\mathbf{Y}_{m(j, k+1)}= & {\left[\begin{array}{llll}
\mathbf{X}_{m(j, k+1)} & \mathbf{X}_{m(j, k)} & \mathbf{X}_{m(j, k-1)} \\
& \cdots & \mathbf{X}_{m\left(j, k-m_{1}+1\right)} & \cdots \\
& \mathbf{X}_{m\left(j, k-m_{N}+1\right)} & \cdots & \mathbf{X}_{m(j, k-m+1)}
\end{array}\right]^{T} }
\end{aligned}
$$

The matrix $\mathbf{D}_{m(j, k)}$ can be formulated as the following expressions

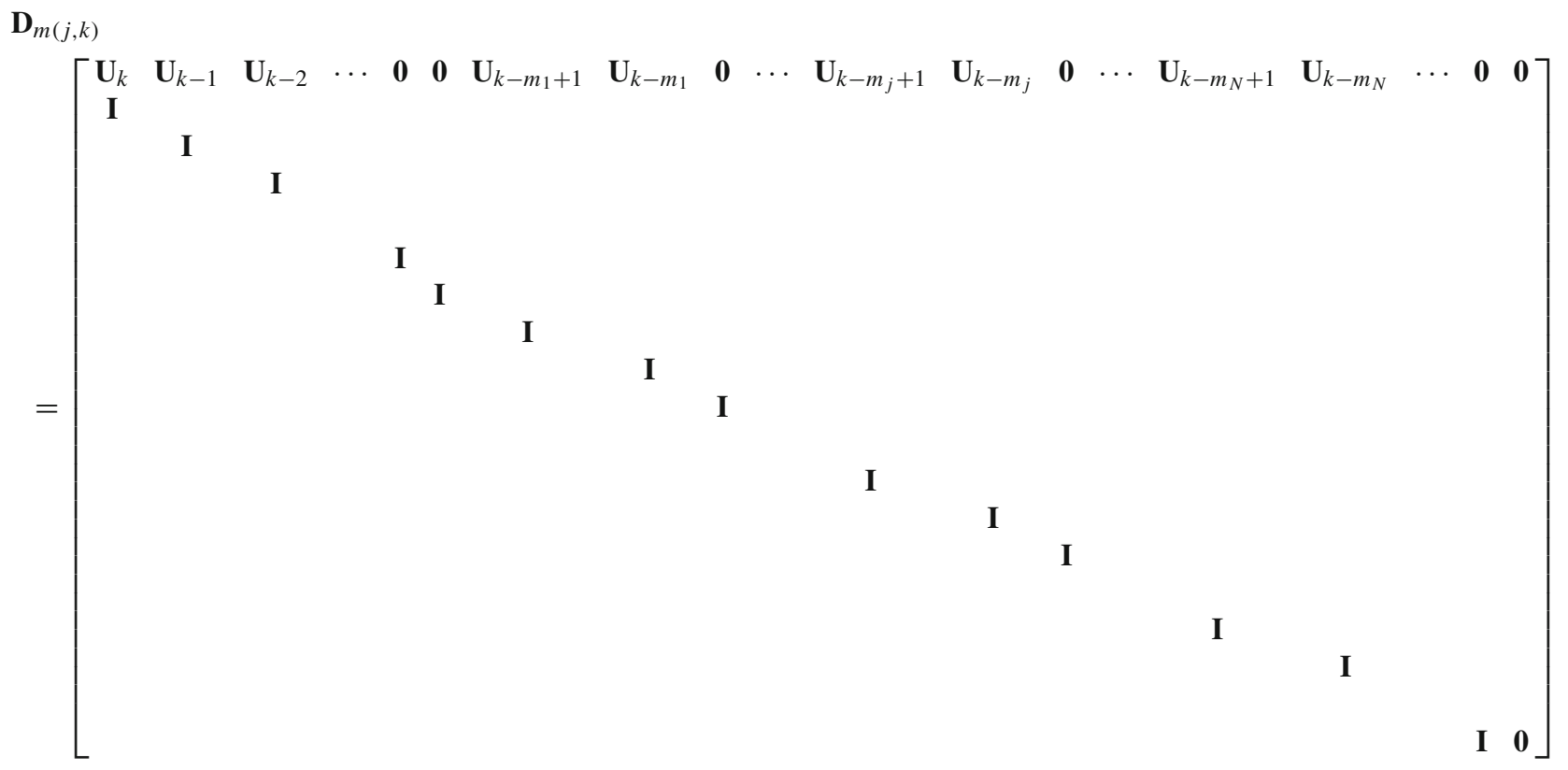

(41) 

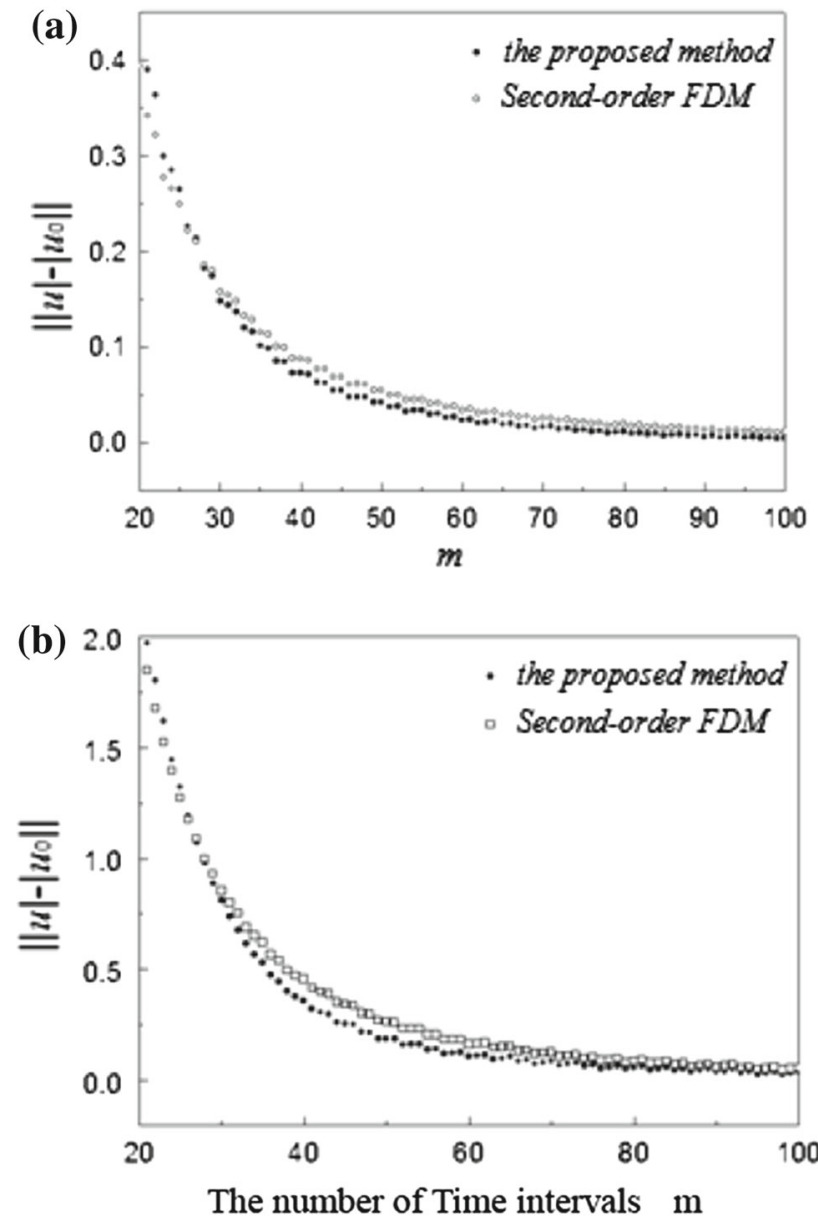

Fig. 2 Convergence of the eigenvalues for different approximation parameters m. a Axial cutting depth $4 \mathrm{~mm}$, rotational speed 5,000 rmp, $\left|u_{0}\right|=3.637$. b Axial cutting depth $3 \mathrm{~mm}$, rotational speed 3,000 rpm, $\left|u_{0}\right|=2.408$

Table 1 The parameters of the dynamic cutting system

\begin{tabular}{lllcl}
\hline Direction & Mode & $\begin{array}{l}\text { Natural } \\
\text { frequency }(\mathrm{Hz})\end{array}$ & $\begin{array}{l}\text { Modal } \\
\text { mass }(\mathrm{kg})\end{array}$ & $\begin{array}{l}\text { Damping } \\
\text { ratios }\end{array}$ \\
\hline $\mathrm{X}$ & 1 & 441.64 & 11.125 & 0.028722 \\
& 2 & 563.6 & 1.4986 & 0.055801 \\
& 3 & 778.6 & 13.063 & 0.058996 \\
$\mathrm{Y}$ & 1 & 516.21 & 1.199 & 0.025004 \\
\hline
\end{tabular}

Further, the concrete parameters in the above matrix can be expressed as

$$
\left\{\begin{array}{l}
\mathbf{U}_{k}=\left(\mathbf{I}-\mathbf{F}_{1}\right)^{-1}\left(\mathbf{F}_{0}+\mathbf{F}_{2}\right) \\
\mathbf{U}_{k-1}=\left(\mathbf{I}-\mathbf{F}_{1}\right)^{-1} \mathbf{F}_{3} \\
\mathbf{U}_{k-2}=\left(\mathbf{I}-\mathbf{F}_{1}\right)^{-1} \mathbf{F}_{4} \\
\mathbf{U}_{k-m_{j}}=\left(\mathbf{I}-\mathbf{F}_{1}\right)^{-1} \mathbf{F}_{j, m} \\
\mathbf{U}_{k-m_{j}+1}=\left(\mathbf{I}-\mathbf{F}_{1}\right)^{-1} \mathbf{F}_{j, m-1}
\end{array}\right.
$$

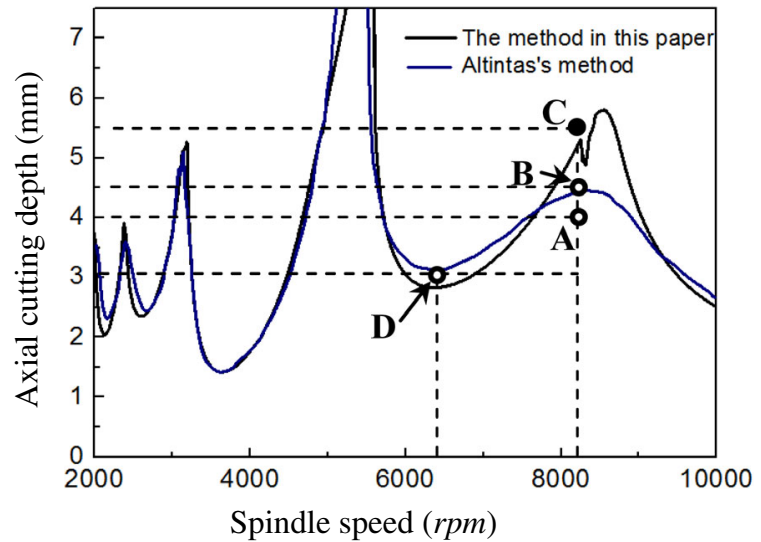

Piont A

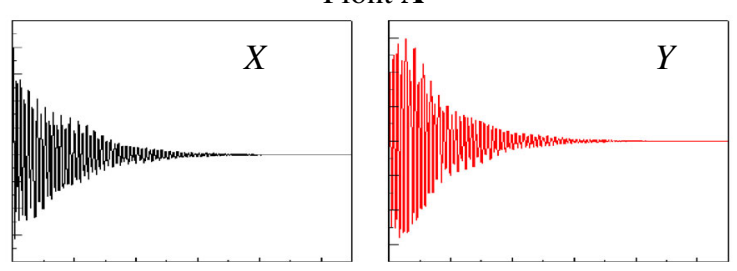

Piont B

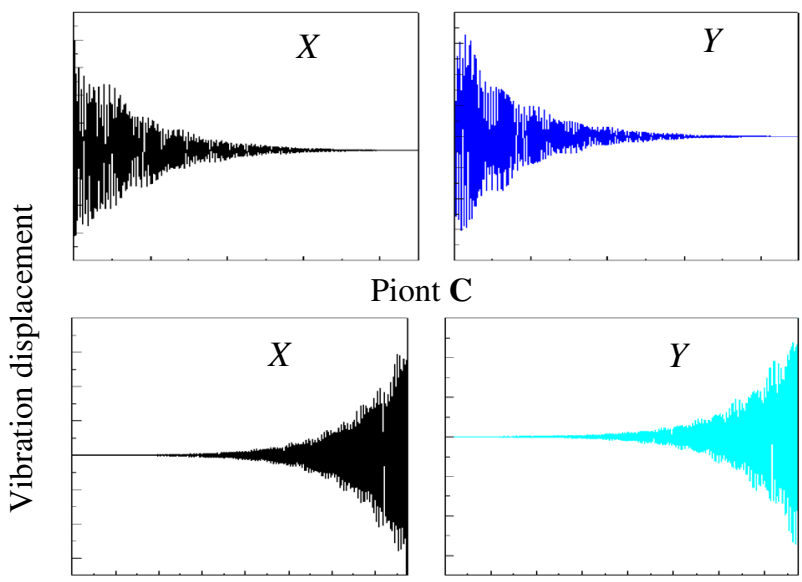

Piont D

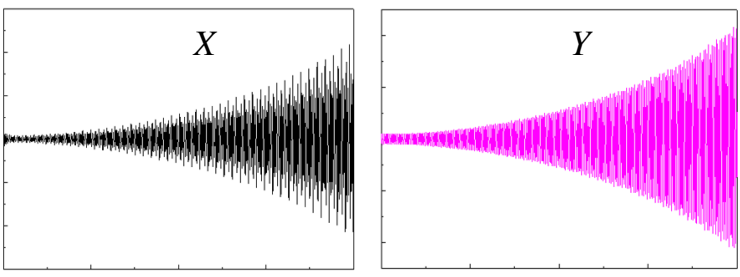

Time

Fig. 3 Comparison of the stability lobes predicted by literatures' method and the proposed method

Then, $\mathbf{Y}_{m}$ can be calculated using $\mathbf{Y}_{0}$ with iterated function (39). The formula can be written as

$\mathbf{Y}_{m}=\mathbf{D}_{m-1} \cdots \mathbf{D}_{2} \mathbf{D}_{1} \mathbf{D}_{0} \mathbf{Y}_{0}$

Defining $\boldsymbol{\Phi}$ is the transfer function matrix of the dynamic machining system with multiple delays, and then $\boldsymbol{\Phi}$ is deter- 


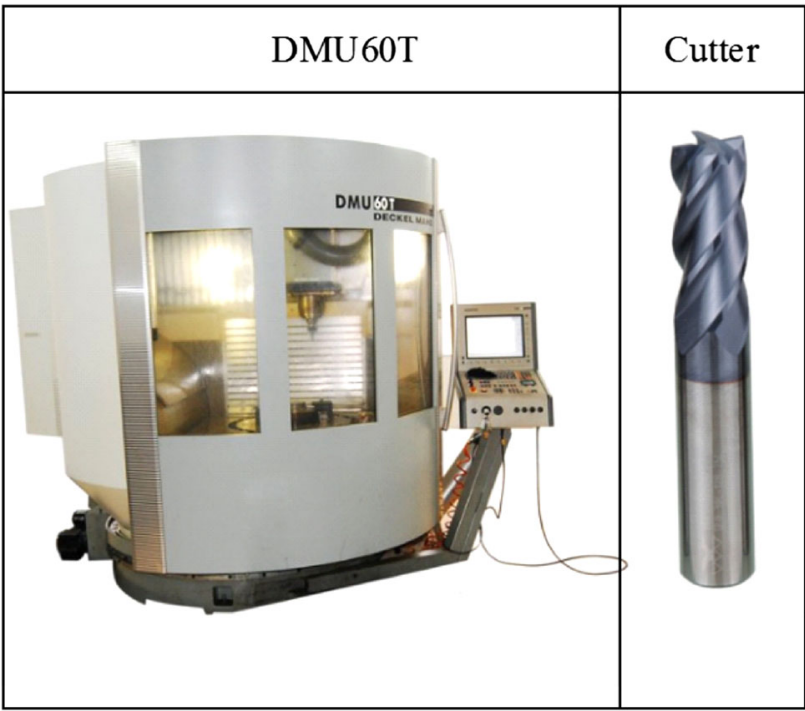

Fig. 4 Machine tool and cutter utilized in the experiment

mined by the matrix in Eq. (43)

$$
\boldsymbol{\Phi}=\mathbf{D}_{m-1} \cdots \mathbf{D}_{2} \mathbf{D}_{1} \mathbf{D}_{0}
$$

Thus, using the above transform function equation and Floquet theory, the stability lobes with multiple delays can be calculated.

\subsection{Convergence estimates}

Considering the convergence of existing methods has been compared in the literatures [37], so here the comparisons of convergence between the proposed method and second-order full discretization method are given. The parameters of the dynamic milling process are the same as those in Insperger's work [4]. In the machining process, down milling is performed, and rotational speeds are 5,000 rpm and 3,000 rpm. The axial cutting depths and the ratio between radial cutting depth and cutter radius are set as $(4 \mathrm{~mm}, 0.4)$ and $(3 \mathrm{~mm}, 0.3)$ correspondingly. As shown in Fig. 2, the differences between the approximate modulus of the critical eigenvalue $|\mu|$ and the exact one $\left|\mu_{0}\right|$ are obtained, where $\left|\mu_{0}\right|$ is determined by using the method in [40] with $m=500$. The results show that the proposed method converges faster than the second-order FDM.

\section{Examples and verifications}

To illustrate the validity of the proposed method, three examples are given and conducted.

4.1 Example I: stability lobe for non-uniform pitch cutter

The dynamic system with variable pitch angle cutter can suppress the self-excited vibration and improve the limit of the dynamic system. The authors use the system in Altintas'
Fig. 5 Modal parameter measurement system

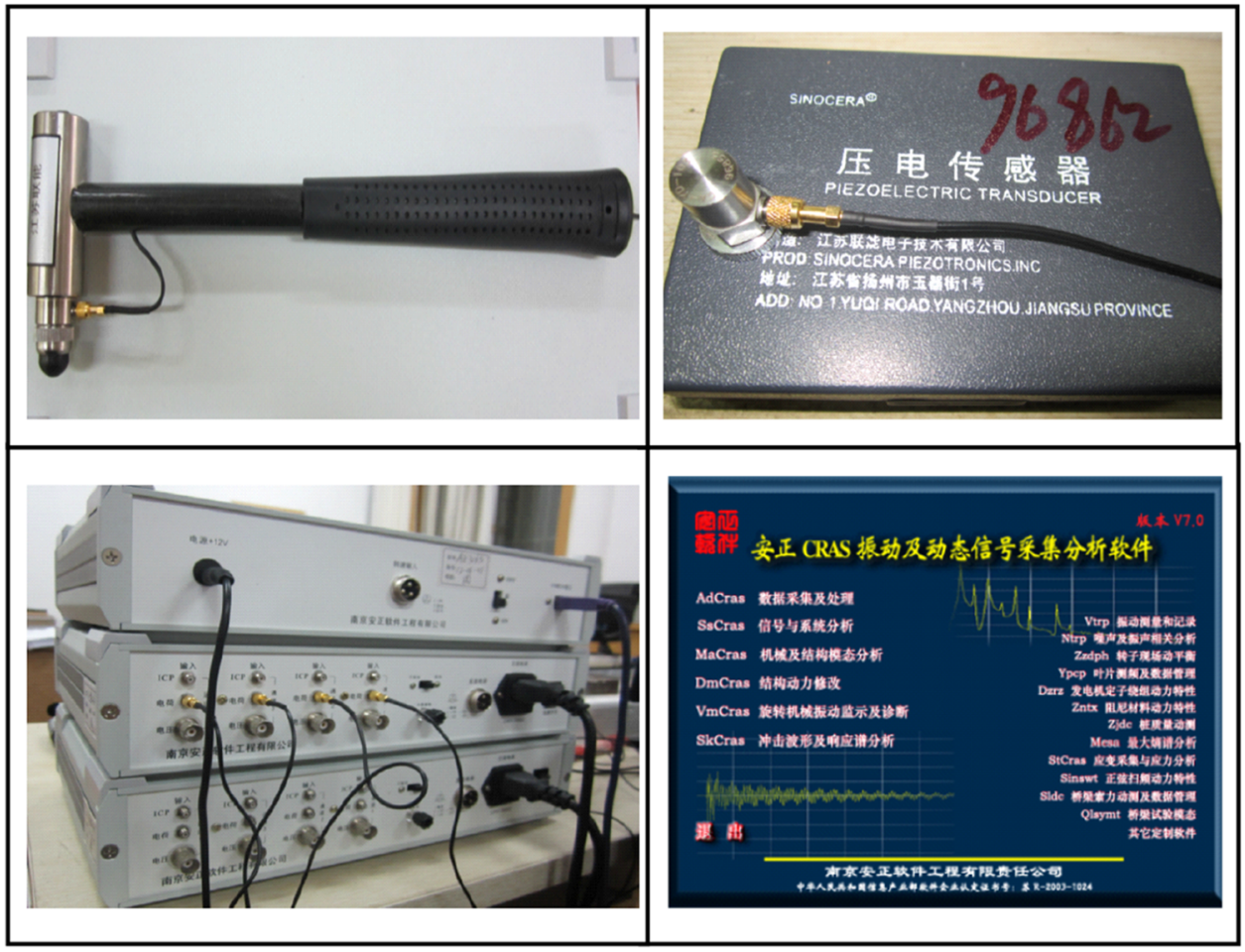


Table 2 Parameters of modal, cutter run-out and cutting force coefficients of the cutter-machine dynamic system

\begin{tabular}{|c|c|c|c|}
\hline $\begin{array}{l}\text { Modal parameters } \\
\text { Mode Y }\end{array}$ & Natural frequency $(\mathrm{Hz})$ & Damping ratios & Modal mass $(\mathrm{Kg})$ \\
\hline 1 & 950 & 0.067 & 1.4858 \\
\hline 2 & 1736 & 0.0122 & 0.8368 \\
\hline 3 & 2225 & 0.0388 & 0.609 \\
\hline Mode X & Natural frequency $(\mathrm{Hz})$ & Damping ratios & Modal mass $(\mathrm{Kg})$ \\
\hline 1 & 891.92 & 0.0289 & 1.615 \\
\hline 2 & 1749.23 & 0.0159 & 0.3864 \\
\hline 3 & 2225 & 0.0423 & 0.6672 \\
\hline $\begin{array}{l}\text { Cutter run-out parameters } \\
\text { Offset (mm) }\end{array}$ & \multicolumn{3}{|l|}{ Location angle (rad.) } \\
\hline 0.0045 & \multicolumn{3}{|l|}{0.889} \\
\hline $\begin{array}{l}\text { Cutting force coefficients } \\
\text { Radial cutting force coefficient (MPa) }\end{array}$ & \multicolumn{3}{|c|}{ Tangent cutting force coefficient (MPa) } \\
\hline 876 & 1,320 & & \\
\hline
\end{tabular}

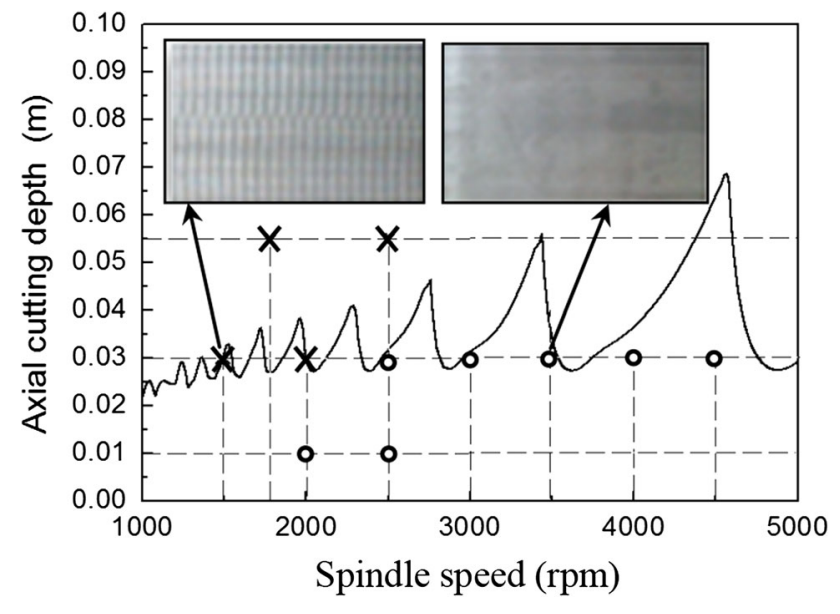

Fig. 6 Stability lobes of the cutter-machine dynamic system

paper to verify the validity of the proposed method in this paper. The parameters of the dynamic system are illustrated in Table 1.

The ratio between radial cutting depth and cutter radius is 0.5 , the pitch angle of cutter is 70-110-70-110, the number of cutter edge is $N=4$, and the cutting force coefficients are $K_{t}=679 \mathrm{MPa}$ and $K_{n}=249.193 \mathrm{MPa}$. Then the stability lobe is predicted using the Altintas' method and the proposed method. The computational results are shown in Fig. 3.

In this figure, three positions, namely point $\mathbf{A}(8,000 \mathrm{rpm}$, $4 \mathrm{~mm})$, point $\mathbf{B}(8,000 \mathrm{rpm}, 4.5 \mathrm{~mm})$, point $\mathbf{C}(8,000 \mathrm{rpm}$, $5.5 \mathrm{~mm})$ and point $\mathbf{D}(6,000 \mathrm{rpm}, 3.1 \mathrm{~mm})$, are selected to compute the vibration displacement in $x$ and $y$ axis direction using the dde23 function of MATLAB2008a. It can be seen that point $\mathbf{A}$, point $\mathbf{B}$ and point $\mathbf{D}$ are stable. Meanwhile, we can see that point $\mathbf{A}$ is under the curves respectively predicted by Altintas' method and the proposed method. For point B, it lies in the stable area calculated by the proposed method, but it is in the unstable area computed with the Altintas' method. In contrast to the case of point $\mathbf{B}$, point $\mathbf{D}$ is under the curve calculated by Altinas' method, but it is above the curve computed using the proposed method. It means that the proposed method in this paper is more accurate.

\subsection{Example II: experiment verification}

In order to illustrate the validity of the proposed method more clearly, as illustrated in Fig. 4, an experiment is carried out on a DMU60T CNC machine.The material of cutter is cemented carbide, the radius of the cutter with uniform pitch angle is $6 \mathrm{~mm}$. The number of cutter edge is 4 , and the helix angle of the cutter is $45^{\circ}$.

The modal parameters of the dynamic system are measured by a CRAS analyzer system shown in Fig. 5. The cutting force coefficients and cutter run-out parameters are derived through machining experiments based on the author's previous works [41]. Table 2 shows the concrete modal parameters, cutting force coefficients and cutter run-out parameters. In the experiment the radial cutting depth is $0.5 \mathrm{~mm}$. Then, as shown in Fig. 6 the stability lobes of the dynamic system are predicted and a series of three axis milling experiments are conducted to verify the proposed method

In the experiment, the parameter combinations of spindle speed and axial cutting depth are given as $(1,500 \mathrm{rpm}$, $0.03 \mathrm{~m}),(1,750 \mathrm{rpm}, 0.05 \mathrm{~m}),(2,000 \mathrm{rpm}, 0.01 \mathrm{~m}),(2,500$ 


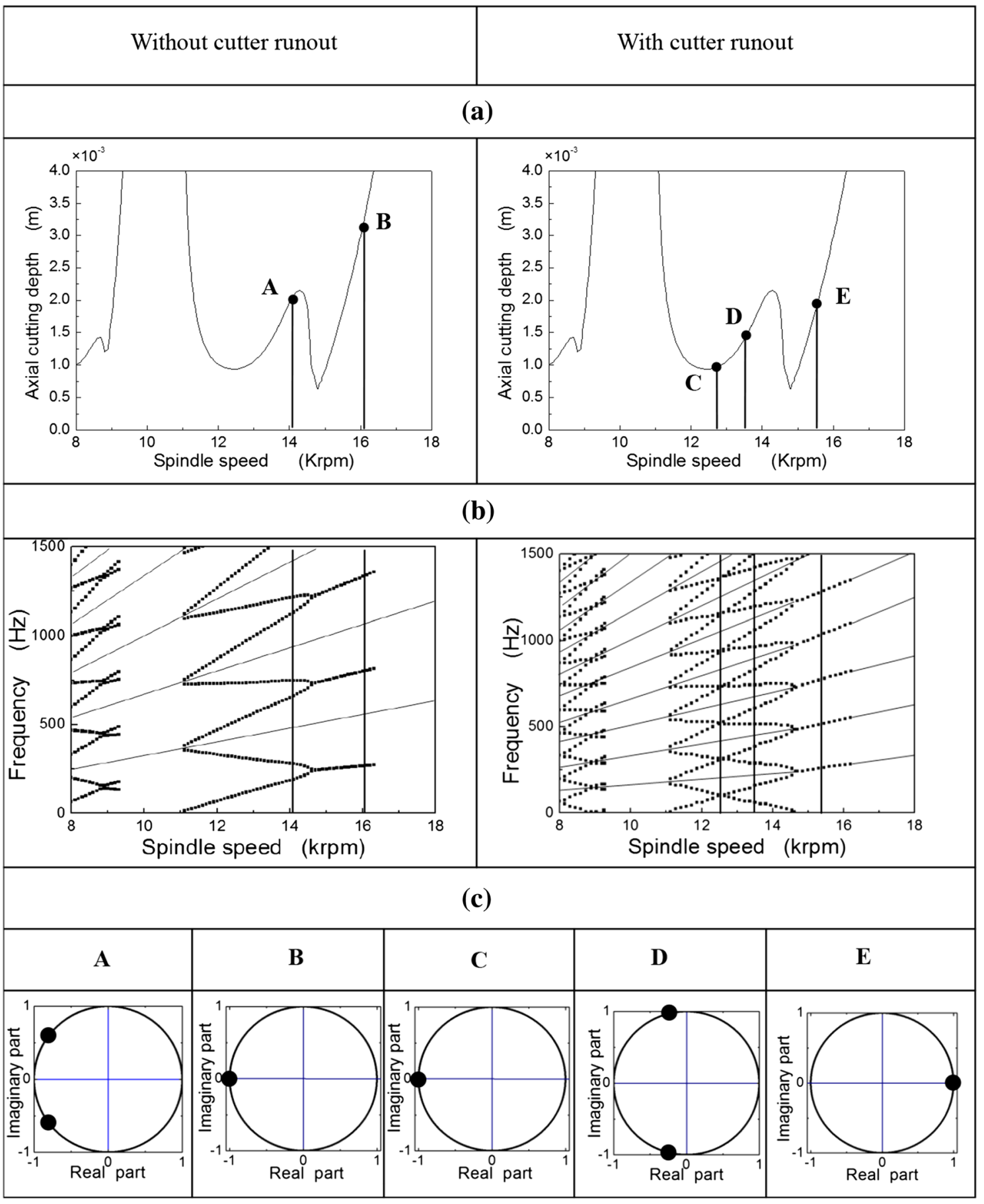

Fig. 7 Stability lobes and chatter frequency when cutting process with and without cutter run-out

rpm, $0.01 \mathrm{~m}),(2,500 \mathrm{rpm}, 0.03 \mathrm{~m}),(2,000 \mathrm{rpm}, 0.05 \mathrm{~m})$, $(3,000 \mathrm{rpm}, 0.03 \mathrm{~m}),(3,500 \mathrm{rpm}, 0.03 \mathrm{~m}),(4,000 \mathrm{rpm}, 0.03 \mathrm{~m})$ and $(4,500 \mathrm{rpm}, 0.03 \mathrm{~m})$. The experimental results prove that the process parameters under the stability limit curve, namely $(2,000 \mathrm{rpm}, 0.01 \mathrm{~m}),(2,500 \mathrm{rpm}, 0.03 \mathrm{~m}),(3,000 \mathrm{rpm}$, $0.03 \mathrm{~m}),(3,500 \mathrm{rpm}, 0.03 \mathrm{~m}),(4,000 \mathrm{rpm}, 0.03 \mathrm{~m})$ and $(4,500$ $\mathrm{rpm}, 0.03 \mathrm{~mm}$ ) are stable, and the parameter combinations over the stability limit curve are also unstable in real machin- ing. These show that the proposed method is of valid and effective.

4.3 Example III: influence of cutter run-out parameters on the stability lobes

Cutter run-out has great effect on the geometric accuracy and cutting forces $[41,42]$. Consequently, it also has contri- 
butionsto the vibration of the dynamic machining process. Therefore, it is essential and necessary to analyze the influence of cutter run-out on the stability lobes and vibration chatter.

Two stability lobes and corresponding chatter frequency charts under with and without cutter run-out are calculated using the method proposed in this paper for down milling process. Cutter run-out parameters are $\rho_{1}=0.9$ and $\rho_{2}=$ 1.1. The meanings of $\rho_{1}=0.9$ and $\rho_{2}=1.1$ are $10 \%$ smaller and $10 \%$ larger than the standard cutting force value for the first and second cutter edge correspondingly. The parameters of the dynamic system are given as follows

$$
\left\{\begin{array}{l}
\mathbf{M}=\left[\begin{array}{cc}
0.046 & 0 \\
0 & 0.046
\end{array}\right] \mathrm{kg} \\
\mathbf{C}=\left[\begin{array}{cc}
4.32 & 0 \\
0 & 4.32
\end{array}\right] \mathrm{Ns} / \mathrm{m} \\
\mathbf{K}=\left[\begin{array}{cc}
9.57 e 5 & 0 \\
0 & 9.57 e 5
\end{array}\right] \mathrm{N} / \mathrm{m}
\end{array}\right.
$$

The parameters of the cutting process, cutter and cutting force coefficients are

$$
\left\{\begin{array}{l}
D=12.75 \mathrm{~mm} \\
f=0.127 \mathrm{~mm} / \text { tooth } \\
a_{r} / D=0.05 \\
K_{t}=536 \mathrm{~N} / \mathrm{mm}^{2} \\
K_{r}=187 \mathrm{~N} / \mathrm{mm}^{2} \\
N=2
\end{array}\right.
$$

where $D$ is the cutter radius, $a_{\mathrm{r}}$ is the radial cutting depth, $f$ is feedrate per-tooth, $K_{\mathrm{t}}$ is the tangent cutting force coefficient, and $K_{r}$ is the radial cutting force coefficient. All the parameters illustrated above can be found in the Insperger's work [43]. Figure 7 shows the calculating results under with and without cutter run-out. From the results we can find that on the one hand cutter run-out has little effect on the stability lobes as showed in Fig. 7(a). On the other hand, cutter run-out has a great influence on the chatter frequencies. As illustrated in Fig. 7(b), the chatter chart has 5 and 3.5 frequency lobes in the spindle speed interval $[8,10] \mathrm{krpm}$ and $[11,12] \mathrm{krpm}$ in milling process without cutter run-out. Whereas, when the chatter chart has 10.5 and 6.5 frequency lobeswith run-out.

Figure 7(c) shows the critical characteristic values of five unstable machining points and their positions on the unit circle. For point A, the frequency belongs to the Quasi-periodic chatter whose critical characteristic values is conjugate complex. For point $\mathbf{B}$, the frequency is period 2 chatter, the critical characteristic values of which is -1 . Point $\mathbf{C}$, point $\mathbf{D}$ and point $\mathbf{E}$ are the critical characteristic values in the machining process with cutter run-out. Among them, period 1 chatter (point E whose critical characteristic values is 1) can be found. However, this phenomenonis not found in the machining process without cutter run-out.

\section{Conclusions}

Based on the author's previous work, a new prediction method of stability limit for the dynamic system with multiple regenerative effect is proposed in this paper. The milling process with non-uniform pitch angle and cutter run-out is first analyzed and related parameters in calculation are derived. Then a mathematical modelof stability prediction for multi-regenerative chatteris established. After that, three examples are given to verify the validity of the proposed method. Experimental and computational results show that the proposed method is able to handle the case of non-uniform pitch angle cutter and incorporate the cutter run-out into the model, at the same time it can calculate the stability lobe with a high accuracy. By means of accurate calculation method of stability lobes and reliable detection system, good parameter combination can be determined for high performance machining according to the obtained stability limit curve.

Acknowledgments The authors really appreciate Professor Insperger's valuable suggestions and great help. This research is supported by NSFC (Nos. 51075054, 11290143 and 51321004) and NBRPC (No. 2011CB706800).

\section{References}

1. Quintana G, Ciurana J (2011) Chatter in machining processes: a review. Int J Mach Tools Manuf 51:363-376

2. Altintas Y, Merdol SD (2007) Virtual high performance milling. CIRP Ann Manuf Technol 56(1):81-84

3. Budak E (2006) Analytical models for high performance milling. Part II: process dynamics and stability. Int J Mach Tools Manuf 46(12-13):1489-1499

4. Insperger T, Stépán G (2004) Updated semi-discretization method for periodic delay-differential equations with discrete delay. Int J Numer Methods Eng 64:117-141

5. Sridhar R, Hohn RE, Long GW (1968) A stability algorithm for the general milling process: contribution to machine tool chatter research. J Eng Ind 90:330-334

6. Campa FJ, Lopez de Lacalle LN, Celaya A (2011) Chatter avoidance in the milling of thin floors with bull-nose end mills: model and stability diagrams. Int J Mach Tools Manuf 51(1):43-53

7. Ahmadi K, Ismail F (2011) Analytical stability lobes including nonlinear process damping effect on machining chatter. Int $\mathrm{J}$ Mach Tools Manuf 51(4):296-308

8. Wan M, Zhang W-H, Dang J-W, Yang Y (2010) A unified stability prediction method for milling process with multiple delays. Int $\mathrm{J}$ Mach Tools Manuf 50:29-41

9. Cao H, Li B, He Z (2012) Chatter stabilityof milling with speedvarying dynamics of spindles. Int J Mach Tools Manuf 52:50-58

10. Tlusty J, Polacek M (1963) The stability of machine tools against self-excited vibrations. ASME Int Res Prod Eng 1:465-474

11. Tobias SA (1969) Machine tool vibration. Blackie, London

12. Altintas Y, Budak E (1995) Analytical prediction of stability lobes in milling. CIRP Ann Manuf Technol 44:357-362

13. Altintas Y, Engin S, Budak E (1999) Analytical stability prediction and design of variable pitch cutters. J Manuf Sci Eng 121:173-178

14. Minis I, Yanushevsky T (1993) A new theoretical approach for the prediction of machine tool chatter in milling. Trans ASME J Eng Ind 115:1-8 
15. Altintas Y, Montgomery D, Budak E (1992) Dynamic peripheral milling of flexible structures. J Eng Ind 114:137-145

16. Budak E (2003) An analytical design method for milling cutters with nonconstant pitch to increase stability, part I: theory. J Manuf Sci Eng 125:29-34

17. Budak E (2003) An analytical design method for milling cutters with nonconstant pitch to increase stability, part 2: application. J Manuf Sci Eng 125:35-38

18. Budak E, Altintas Y (1998) Analytical prediction of chatter stability in milling-part I: general formulation. J Dyn Syst Meas Control 120:22-30

19. Budak E, Altintas Y (1998) Analytical prediction of chatter stability in milling - part II: application to commonmilling systems. J Dyn Syst Meas Control 120:30-36

20. Altintas Y, Shamoto E, Lee P, Budak E (1999) Analytical prediction of stability lobes in ball-end-milling. Trans ASME J Manuf Sci Eng 121:586-592

21. Merdol SD, Altintas Y (2004) Mechanics and dynamics of serrated cylindrical and tapered end mills. J Manuf Sci Eng 126(2):317-326

22. Turner S, Merdol D, Altintas Y, Ridgway K (2007) Modelling of the stability of variable helix end mills. Int J Mach Tools Manuf 47(9):1410-1416

23. Dombovari Z, Stepan G (2012) The effect on helix angle variation on milling stability. J Manuf Sci Eng 134(4):051015.1-051015.6

24. Kivanc EB, Budak E (2003) Development of analytical endmill deflection and dynamics models. ASME Conf Proc 2003:85-94

25. Kivanc EB, Budak E (2004) Structural modeling of end mills for form error and stability analysis. Int J Mach Tools Manuf 44:11511161

26. Ozlu E, Budak E (2007) Analytical modeling of chatter stability in turning and boring operations-part II: experimental verification. J Manuf Sci Eng 129:733-739

27. Ozlu E, Budak E (2007) Analytical modeling of chatter stability in turning and boring operations-part I: model development. J Manuf Sci Eng 129:726-732

28. Insperger T, Mann BP, Surmann T, Stépán G (2008) On the chatter frequencies of milling processes with runout. Int $\mathrm{J}$ Mach Tools Manuf 48:1081-1089

29. Insperger T, Stépán G, Bayly PV et al (2003) Multiple chatter frequencies in milling processes. J Sound Vib 262(2):333-345
30. Insperger T, Mann BP, Stépán G et al (2003) Stability of up-milling and down-milling, part 1: alternative analytical methods. Int J Mach Tools Manuf 40(1):25-34

31. Insperger T, Stepan G (2002) Semi-discretization method for delayed systems. Int J Numer Methods Eng 55(5):503-518

32. Catania G, Mancinelli N (2011) Theoretical-experimental modeling of milling machines for the prediction of chatter vibration. Int J Mach Tools Manuf 51:339-348

33. Smith S, Tlusty J (1993) Efficient simulation programs for chatter in milling. CIRP Ann Manuf Technol 42:463-466

34. Zhao MX, Balachandran B (2001) Dynamics and stability of milling process. Int J Solids Struct 38:2233-2248

35. Ding Y, Zhu L, Zhang X, Ding H (2011) Numerical integration method for prediction of milling stability. J Manuf Sci Eng 133:031005-031009

36. Ding Y, Zhu L, Zhang X, Ding H (2010) A full-discretization method for prediction of milling stability. Int J Mach Tools Manuf 50:502-509

37. Ding Y, Zhu L, Zhang X, Ding H (2010) Second-order fulldiscretization method for milling stability prediction. Int J Mach Tools Manuf 50:926-932

38. Zhang XJ, Xiong CH, Ding Y, Xiong YL (2011) Variable-step integration method for milling chatter stability prediction with multiple delays. Sci China Technol Sci 54:3137-3154

39. Insperger $T$ (2010) Full-discretization and semi-discretization for milling stability prediction: some comments. Int J Mach Tools Manuf 50(7):658-662

40. Guo Q, Sun Y, Jiang Y (2012) On the accurate calculation of milling stability limits using third-order full-discretization method. Int $\mathbf{J}$ Mach Tools Manuf 62:61-66

41. Sun Y, Guo Q (2011) Numerical simulation and prediction of cutting forces in five-axis milling processes with cutter run-out. Int $\mathbf{J}$ Mach Tools Manuf 51(10-11):806-815

42. Sun Y, Guo Q (2012) Analytical modeling and simulation of the envelope surface in five-axis flank milling with cutter runout. Trans ASME J Manuf Sci Eng 134(2):021010-1-021010-11

43. Insperger T, Stepan G, Turi J (2008) On the higher-order semidiscretizationsfor periodic delayed systems. J Sound Vib 313(12):334-341 